\title{
Quiescent Platelets Stimulate Angiogenesis and Diabetic Wound Repair
}

\section{Citation}

Pietramaggiori, Giorgio, Saja S. Scherer, Jasmine C. Mathews, Tony Gennaoui, Luca Lancerotto, Gina Ragno, C. Robert Valeri, and Dennis P. Orgill. 2010. "Quiescent Platelets Stimulate Angiogenesis and Diabetic Wound Repair." Journal of Surgical Research 160 (1) (May): 169-177. doi:10.1016/j.jss.2008.09.010.

\section{Published Version}

doi:10.1016/j.jss.2008.09.010

\section{Permanent link}

http://nrs.harvard.edu/urn-3:HUL.InstRepos:32659593

\section{Terms of Use}

This article was downloaded from Harvard University's DASH repository, and is made available under the terms and conditions applicable to Other Posted Material, as set forth at http:// nrs.harvard.edu/urn-3:HUL.InstRepos:dash.current.terms-of-use\#LAA

\section{Share Your Story}

The Harvard community has made this article openly available.

Please share how this access benefits you. Submit a story.

\section{Accessibility}




\title{
Quiescent platelets stimulate angiogenesis and diabetic wound repair
}

\author{
Giorgio Pietramaggiori, MD, $\mathrm{PhD}^{1,2}$, Saja S. Scherer, $\mathrm{MD}^{1}$, Jasmine C. Mathews, $\mathrm{MA}^{1}$, Tony \\ Gennaoui, BS ${ }^{3}$, Luca Lancerotto, MD $^{2}$, Gina Ragno, BA ${ }^{3}$, C. Robert Valeri, MD ${ }^{3}$, and Dennis \\ P. Orgill, MD, PhD ${ }^{1}$ \\ ${ }^{1}$ Division of Plastic Surgery, Brigham and Women's Hospital and Harvard Medical School, 75 \\ Francis Street Boston, MA 02115 \\ ${ }^{2}$ Division of Plastic Surgery, Civil Hospital, University of Padova, Italy \\ ${ }^{3}$ Naval Blood Research Laboratory, Boston, MA
}

\section{Abstract}

Introduction-Platelets partake in hemostasis, wound healing and tumor growth. Although platelet-rich-plasma (PRP) has been used in surgery for several years, its mechanism of action and application methods are still poorly characterized.

Materials and Methods-A single unit of human platelets obtained by plateletpheresis was diluted in plasma and divided into three equal volumes. One volume was stored at room temperature as fresh platelets (RT), another volume frozen by storage at $-80^{\circ} \mathrm{C}(\mathrm{FZ})$ and the third volume frozen at $-80{ }^{\circ} \mathrm{C}$ with $6 \%$ DMSO (FZ6). Plasma (PL) was used as control. Using flow cytometry, platelets were tested for platelet glycoprotein GPIb and annexin V binding, as survival and activation markers, respectively. Hemostatic function was assessed by thromboelastometry.

In vivo, platelets were topically applied on $1 \mathrm{~cm}^{2}$, full-thickness wounds on $\mathrm{db} / \mathrm{db}$ mice ( $\mathrm{n}=10 /$ group) and healing was staged microscopically and macroscopically.

Results-All platelet preparations showed hemostatic ability. RT platelets were GPIb positive (nonactivated-quiescent platelets) and stimulated angiogenesis by 3 -fold, and cell proliferation by 4-fold in vivo. FZ platelets were positive for annexin $\mathrm{V}$, indicating activated platelets and, in vivo, increased only wound granulation. FZ6 platelets contained 30\% nonactivated-quiescent and 50\% activated platelets and stimulated granulation, angiogenesis, cell proliferation and promoted reepithelialization in vivo.

Conclusions-Platelets showed distinct mechanisms to induce hemostasis and wound healing. Quiescent platelets are required to induced angiogenesis in vivo. Platelets stored at room temperature and frozen with $6 \% \mathrm{DMSO}$ and stored at $-80{ }^{\circ} \mathrm{C}$ achieved optimal wound healing in diabetic mice.

(C) 2010 Elsevier Inc. All rights reserved.

Corresponding Authors: Dennis P. Orgill MD, PhD Division of Plastic Surgery 75 Francis Street Brigham and Women's Hospital Boston, MA 02115 (P) 617-732-5456 (F) 617-730-2855 dorgill@partners.org C. Robert Valeri, MD Naval Blood Research Laboratory navblood@nbrl.org .

Publisher's Disclaimer: This is a PDF file of an unedited manuscript that has been accepted for publication. As a service to our customers we are providing this early version of the manuscript. The manuscript will undergo copyediting, typesetting, and review of the resulting proof before it is published in its final citable form. Please note that during the production process errors may be discovered which could affect the content, and all legal disclaimers that apply to the journal pertain. 


\section{Introduction}

Impaired wound healing is a major clinical problem that particularly affects the diabetic population.(1) Poor vascularization seems to be a major reason for this limited healing capacity, (2) and many strategies to stimulate angiogenesis have been tested, ranging from recombinant growth factors to mechanical stimulation of wound tissues. $(3,4)$

Platelets are anucleated cells traditionally characterized as primary effectors of hemostasis. (5) Only recent advances in protein profiling techniques have advanced our understanding of the broader biological function of platelets, ranging from wound healing and tumor growth to inflammation and regeneration.(6) These methodologies have characterized more than 20 angiogenetic growth factors contained in the proteome of platelets.(5)

In surgery, platelets have been used to promote bone and soft tissue healing,(7) by concentrating stimulating cytokines at the site of injury.(8) With the formation of the blood clot during wound healing, platelets provide a temporary scaffold for the ingrowth of cells and modulate angiogenesis, through a complex and undefined series of cell and growth factor mediated events.(8-10) The proteome of platelets is rich in several pro-angiogenic and anti-angiogenic factors. $(5,11,12)$ The recent discovery that pro-angiogenic and anti-angiogenic factors are released from platelets in a sequential manner may explain how platelets affect angiogenesis and wound healing.(9)

Early in wound healing, angiogenesis is essential to the repair process and once healing has ceased endothelial cells in the wound bed revert to a quiescent state and undergo apoptosis. (13) This may be explained by the increase of thrombin and collagen in maturing wounds that leads to activation of the anti-angiogenic factors and the subsequent release of angiogenesis inhibitors from stromal cells and platelets, as previously documented. $(9,14)$ Studies have reported disappointing results to improve wound healing using growth factors(15-17) and platelets activated with thrombin.(18)

In this report, we studied human platelets stored at room temperature for 2 days, human platelets frozen by storage at $-80 \mathrm{C}$, and human platelets frozen with $6 \%$ DMSO by storage at $-80 \mathrm{C}$ to correlate in vitro measurements of the platelet products to wound healing in diabetic mice.

\section{Methods}

\section{Collection of the platelets}

At the Oklahoma Blood Institute, Oklahoma City, OK, PLTs were collected from the human blood donor by plateletpheresis using the instrument manufactured by COBE Spectra, Gambro BCT, Lakewood, $\mathrm{CO}$ at a ratio of $10 \mathrm{vol}$ of blood to $1 \mathrm{vol}$ of ACD (Formula A). The volunteer donor met the requirements of the AABB and took no medication known to affect PLT function for 10 days before donation. The study was reviewed and approved by the Institutional Review Board for Human Research, Oklahoma Blood Institute, Oklahoma City, OK. Informed consent was obtained from the donor. The PLTs were leukoreduced with a total WBC count of $5 \times$ $10^{6}$, contained more than $4.0 \times 10^{11}$ PLTs, and were stored in two 200 - to $300-\mathrm{mL}$ volumes of plasma in 1000-mL CLX plastic bags.

\section{Liquid preservation at $22^{\circ} \mathrm{C}$}

PLTs collected and stored in 1000-mL CLX (tri-2-ethylhexyl trimellitate) plastic bags were stored in a shipping container that maintained the temperature at room temperature during transportation by air from Oklahoma to Boston on the day of collection. Twenty-four hours after collection and transportation to Boston, the two 250-300 ml volumes were pooled and 
divided into three equal volumes. One volume was stored at room temperature at $22 \mathrm{C}$ (room temperature) on an Eberbach shaker for 24 hours prior to testing.

\section{Cryopreservation of the PLTs}

A volume of 27 percent DMSO in 0.9 percent $\mathrm{NaCl}$ was added to second vol of the PLT-rich plasma to achieve a final concentration of 6 percent DMSO in a 1000-mL polyvinylchloride (PVC) plastic bag. To the third volume of the PLT-rich plasma, a volume in 0.9 percent $\mathrm{NaCl}$ was added equivalent to the volume of DMSO solution added to the second volume of platelet rich plasma. The PLTs preserved with or without DMSO were transferred into a 300-mL PVC plastic bag and centrifuged at $1250 \mathrm{~g}$ for 10 minutes. All the supernatant solution was removed. This reduced the residual amount of DMSO in the DMSO frozen units by at least 95 percent. The 300-mL PVC plastic bag containing $10 \mathrm{~mL}$ of the PLT concentrate was placed in a polyester plastic bag inside a rigid cardboard box, and the PLTs were frozen in an upright -80 $\mathrm{C}$ mechanical freezer for 18 hours. Before thawing, the polyester plastic bag was removed from the PVC bag containing the PLTs. The PLTs were thawed in a thawing bath (Thermogenesis, Rancho Cordoba, CA) maintained at $36^{\circ} \mathrm{C}$ in approximately 5 minutes. The PLTs were diluted with 0.9 percent $\mathrm{NaCl}$ and stored at room temperature for as long as 6 hours without agitation prior to testing. The freeze-thaw recovery values were determined from the PLT count measured with an automated blood cell counter (Coulter ACT5, Beckman-Coulter Corp, Hialeah, FL) and the volume of the PLTs before and after the freeze-thaw procedures. The thromboelastogram measurement was made on platelet products treated with $0.2 \mathrm{~mol} / \mathrm{L} \mathrm{CaCl} 2$ (Thromboelastogram Hemostasis Analyzer 500, Haemoscope Corp., Miles, IL). The R time measurement in the thromboelastogram was determined as the period of time to the initiation of the clot formation by the study samples.(19) The platelets frozen with and without DMSO and stored at $-80 \mathrm{C}$ were thawed and diluted with autologous plasma prior to testing in the thromboelastogram.

\section{Flow cytometry testing}

Anti-CD41a-APC allophycocyanin (GPIIb, clone HIP8), anti-CD42b-PE phycoerythrin (PE; GPIb, clone HIP1), annexin V-fluorescein isothiocyanate (FITC; all three reagents purchased from BD Biosciences PharMingen, San Diego, CA) were used in the testing. PLT preparations were labeled as previously described.(20) Briefly, PLTs were diluted in modified HEPESbuffered Tyrode solution and labeled with the indicated antibodies in buffer alone or in the presence of $3 \mathrm{mmol}$ per L calcium chloride and $2.5 \mathrm{mmol}$ per L Gly-Pro-Arg-Pro, which inhibited fibrinogen polymerization. Incubations were stopped by dilution in HEPES-buffered Tyrode solution containing 1 percent ultrapure formaldehyde (Polysciences, Warrington, PA). Nonspecific antibody background binding was determined with the appropriately labeled isotypic control immunoglobulin G. The prepared samples were analyzed in a flow cytometer (Coulter FC500, Beckman-Coulter) which was calibrated daily with calibration beads (FlowCheck and Flow-Set, Beckman-Coulter). Appropriate color compensation was established for FITC and PE with single-labeled controls. PLTs were identified on the basis of their characteristic log forward and side light scatter and binding of CD41a-APC (GPIIb). A minimum of 5000 PLTs were collected per sample, and data were saved in flow cytometry standard listmode files. The testing of the PLTs to measure the mean fluorescence intensity (MFI) of GPIb and annexin V binding on PLTs and PLT microparticles on a gated FL1 versus FL2 dotplot produced four quadrants in the Coulter FC500 flow cytometer. Quadrant 1 detected the MFI of normal GPIb and reduced annexin V-binding PLTs. Quadrant2 detected the MFI of reduced GPIb and increased annexin V-binding PLTs. Quadrant 3 detected MFI of reduced GPIb and reduced annexin V binding of PLT microparticles, and Quadrant 4 detected MFI of reduced GPIb and increased annexin V binding of PLT microparticles. The total MFI of GPIb and annexin V binding to PLTs in Quadrants 1 and 2 was calculated from the total number of PLTs in $\mathrm{C} 1$ and $\mathrm{C} 2$ quadrants and the MFI that was measured in the $\mathrm{C} 1$ and $\mathrm{C} 2$ quadrants. 
Measurements were made of the MFI of the normal GPIb and reduced annexin V binding for all the PLTs in C1 quadrant, the MFI of the reduced GPIb and increased annexin V binding for all the PLTs in C2 quadrant, and the ratio of the total GPIb MFI and total annexin V MFI in $\mathrm{C} 1$ and $\mathrm{C} 2$ quadrants. The percentage of PLT microparticles in the $\mathrm{C} 4$ quadrant was also measured for the PLTs frozen by the two different freezing procedures and for the liquidpreserved PLTs stored at $22^{\circ} \mathrm{C}$ for 2 days.

\section{Wound Model \& Treatment Procedure}

Homozygous genetically diabetic 8-12 week-old, Lep/r - db/db male mice (strain C57BL/KsJ$\mathrm{Lepr}^{\mathrm{db}}$ ) were used under an approved animal protocol in an AAALAC accredited facility. The day prior to surgery, hair was clipped and depilated (Nair®, Church \& Dwight Co., Princeton, $\mathrm{NJ})$. On the day of the surgery, animals were weighed and anesthetized with $60 \mathrm{mg} / \mathrm{kg}$ Nembutal (Pentobarbital). A dorsal $1.0 \mathrm{~cm}^{2}$ area of skin and panniculus carnosus was excised and the wounds were photographed. Wounds were then photographed and individually sealed with semi-occlusive polyurethane dressings (Tegaderm ${ }^{\mathrm{TM}}, 3 \mathrm{M}$, St. Paul, MN) that was kept until day 7. Injection of platelets preparations $(100 \mu \mathrm{l}$ at $1 \times 109$ platelets per $\mathrm{ml}$ or plasma) using a 30 gauge needle through the dressing into randomly selected wounds followed. Platelet preparations were administered only on the day of the surgery. Groups were categorized and compared as follows: 1 . PL $=$ Plasma Treated $(\mathrm{n}=10) ; 2 . \mathrm{FZ}=$ platelets frozen without DMSO at $-80 \mathrm{C}$ after thawing $(\mathrm{n}=10) ; 3$. FZ6 $=$ platelets frozen with $6 \% \mathrm{DMSO}$ at $-80 \mathrm{C}$ after thawing $(\mathrm{n}=10) ; 4$. $\mathrm{RT}=$ Liquid preserved platelets stored at room temperature for 2 days $(\mathrm{n}=10)$.

\section{Wound Closure Analysis}

Digital photographs captured on day 7 were compared with initial photographs (POD 0) by two independent treatment-blinded observers using planimetric methods (Image J, NIH, Bethesda, MD). Wound closure was quantified by measuring contraction (C), re-

epithelialization (E) and open wound $(\mathrm{O})$ as a percentage of the original wound area. The sum of contracted, re-epithelialized, and open wound areas equals $100 \%$ of the original wound size. (3)

\section{Microscopic Analysis}

Central wound cross-sections ( $\mathrm{n}=10$ per group) were embedded in paraffin, sectioned and stained according to routine Hematoxylin and Eosin (H\&E) protocols. Panoramic crosssectional digital images of each wound were prepared using Adobe Photoshop CS Software (Adobe Systems Incorporated, San Jose, CA).

These sections were analysed with digital planimetry (Image J, NIH, Bethesda, MD) by two independent treatment-blinded observers, to quantify the wound tissue. Granulation tissue in plasma treated wounds was arbitrarily set to $100 \%$.

\section{Immunohistochemistry}

Paraffin-embedded sections ( $\mathrm{n}=10$ per group) were re-hydrated and antigen was retrieved for Ki-67 analysis by microwaving in $10 \mathrm{mM}$ sodium citrate ( $\mathrm{pH}$ 6.0) for 10 minutes. Sections for platelet endothelial cell adhesion molecule-1 (PECAM-1) were treated with $40 \mu \mathrm{g} / \mathrm{ml}$ proteinase K (Roche Diagnostics Corp.) for 25 minutes at $37^{\circ} \mathrm{C}$. PECAM-1, (Pharmingen, San Jose, CA) and Ki-67 (Dako Corp., Carpinteria, CA) primary antibodies were incubated at $4^{\circ}$ C overnight. PECAM-1, and Ki-67 signals were intensified using the tyramide amplification system (Perkinelmer, Boston, MA).

In PECAM-1 stained slides, the total number of blood vessels (positive for PECAM-1) was counted using 40x magnification. 
In Ki-67 stained slides, the ratio of proliferating nuclei (positive for Ki-67) over total nuclei was quantified using 40x magnification.

10 microscopic fields at 40x magnification were used in each treatment arm and immunolocalization condition.

\section{Wound Watch Staging System: Quantification of Vascular Area and Cell Proliferation}

We analyzed our immunohistochemical studies according to a wound watch staging system as previously described.(21) High power images of stained sections were used to quantify the degree of proliferation and vascularization and compare treatments to spontaneous healing. Three digital images of PECAM-1 and Ki-67 stained slides were captured for each sample, one in the middle and two on the edges of the wound bed. Pictures were viewed with Adobe Photoshop CS Software, and blood vessels and proliferating nuclei in each high-powered field were marked and counted and expressed as a ratio of proliferating nuclei (Ki-67-positive) to total nuclei.

Ratios were calculated between results obtained from the centre of the lesions and from the edges of each treatment group to the plasma treated group.

15 microscopic fields at 40x magnification were used in each treatment arm.

\section{Statistical Analysis}

Values are expressed as mean \pm standard deviation in the text and figures. One-way analysis of variance and $a d$ hoc LSD tests were used to determine the significance of differences between treatment modes. Multivariate analysis was performed using Statistica v7.0 (StatSoft, Inc, Tulsa, OK). A P-value of less than 0.05 was considered significant.

\section{Results}

\section{In vitro characterization of platelets}

As a consequence of the exposure to temperatures of $-80 \mathrm{C}$, some of the platelets may be destroyed and produce platelet microparticles. The in vitro freeze-thaw recovery, which reports the percent of the original platelets that were preserved with freezing, was $72 \%$ in the platelets frozen without DMSO and increased up to $94 \%$ with the addition of DMSO prior to freezing. DMSO increased the in vitro recovery of platelets by $22 \%$ when compared to platelets frozen without DMSO by storage at $-80 \mathrm{C}$.

In addition to the number of platelets preserved by freezing with or without DMSO at $-80 \mathrm{C}$, the function of the platelets was assessed. Platelet glycoprotein GPIb and platelet annexin V binding were used as markers of function. Nonactivated-quiescent platelets expressed GPIb reported on the $\mathrm{Y}$ axis of the flow cytometry diagrams and activated platelets identified by annexin $\mathrm{V}$ binding on the $\mathrm{X}$ axis (Fig. 1).

From this analysis of the flow cytometry, RT platelets were found to be homogeneously positive for GPIb and negative for annexin V (Fig. 1a), as opposed to platelets frozen without DMSO at $-80 \mathrm{C}$ that were $80 \%$ positive for annexin $\mathrm{V}$, and mostly negative for GPIb. The addition of $6 \%$ DMSO before freezing at $-80 \mathrm{C}$ produced a bimodal population of platelets consisting of $33 \%$ GPIb positive platelets and $50 \%$ annexin $\mathrm{V}$ positive platelets.

Figure 2 reports studies to assess platelet function by testing in the thromboelastogram. In this study the thromboelastogram was used to test the platelet products. The R time (in minutes) indicates the period of time for the initiation of fibrin formation. The $\mathrm{K}$ time (in minutes) the time needed to reach a specific clot strength; the angle measures the onset of fibrin crosslinking, 
MA or maximum amplitude (in $\mathrm{mm}$ ) measures the fibrin clot. The period of time required for the initiation of the formation of the fibrin clot (R time) was 13.6 minutes for RT platelets (Fig. 2a), when the same platelets were adjusted to $1 \times 10^{9}$ platelets per ml of plasma, the $\mathrm{R}$ time was reduced to 5 minutes (Fig. 2b). At the same concentration FZ and FZ6 platelets showed R times only slightly extended compared to RT platelets achieving a clot in 7.3 and 7.6 minutes, respectively (Fig. 2c,d).

\section{Wound Closure}

All samples were concentrated to $1 \times 10^{9}$ platelets per ml of plasma. Platelets frozen with $6 \%$ DMSO increased wound closure $(\mathrm{p}<0.05)$ compared to plasma and platelets frozen without DMSO (Fig3a, b) on day 7.

In addition to absolute wound closure, wound contraction and re-epithelialization were studied as the two main mechanisms contributing to healing. RT platelets produced a 2 -fold increase in wound contraction ( $<<0.05$, Fig.3c), while FZ6 platelets mainly stimulated wound reepithelialization ( $\mathrm{p}<0.05$, Fig. 3d) compared to plasma.

\section{Histologic analysis}

While plasma treated wounds showed moderate amount of granulation tissue, the platelet producets tended to increase the deposition of newly formed tissue (Fig. 4a). In particular, wounds treated with frozen platelets, with or without 6\% DMSO, showed a 2.5 and 1.9-fold increase $(\mathrm{p}<0.05)$ in granulation tissue area respectively (Fig. 4b). Granulation tissue thickness was also measured and FZ6 and FZ platelets produced a 1.9 and 1.6-fold increase $(\mathrm{p}<0.05)$ compared to PL, respectively (Fig. 4c).

Wound tissues were stained for PECAM-1, a pan-endothelial marker (Fig. 5a). FZ6 and RT platelets increased $(\mathrm{p}<0.05)$ wound vascularity, with 32 and 31 blood vessels/hpf compared to plasma (11 vessels/hpf, Fig. 5a,b). Platelets frozen without DMSO produced only a trend toward increased vascularity compared to plasma (19.7 blood vessels/hpf, Fig.5a,b). Cells in active proliferation in the granulation tissue were stained for Ki-67. FZ6 and RT platelets produced increased cell proliferation $(\mathrm{p}<0.01)$ with up to $49 \%$ and $44 \%$ positive cells respectively compared to plasma on day 7 (Fig.6a,b).

\section{The Wound Watch Staging System}

During healing, as during tumor growth, not only the absolute presence of vasculature is important, but also the ability of the vessels to deliver nutrients and remove toxic metabolites, ultimately promoting wound cells vitality and proliferation is crucial. As a consequence, we developed a two dimensional system based on both vascularity and cell proliferation to stage wound healing. Plasma, as liquid phase control, was arbitrary given a value of 1 and the increases or decreases over plasma were calculated for each platelet product. From this analysis it was possible to see that RT and FZ6 platelets stimulated both parameters with 2.8- and 2.9fold increase in vascularity (Fig.7) and up to 4 - and 4.5 -fold increase in cell proliferation respectively (Fig.7). The wound healing stimulation induced by FZ platelets fell in between the control and the other two groups with 1.7-fold increase in vascularity and 1.2-fold increase in cell proliferation (Fig. 7).

\section{Discussion}

In this study we observed that in vitro manipulation of platelets did not decrease their clotting in the thromboelastogram, but profoundly affected their wound healing function. Angiogenesis and cell proliferation in wounds in diabetic mice were observed with human platelets preserved in the liquid state at room temperature for 2 days and platelets frozen with 6\% DMSO by storage 
at $-80{ }^{\circ} \mathrm{C}$. On the other hand, granulation tissue formation was stimulated by activated platelets derived by platelets frozen without DMSO by storage at $-80^{\circ} \mathrm{C}$. The combination of activated and nonactivated-quiescent platelets provided by FZ6 preparation, achieved the best results in the wound healing in diabetic mice.

To study the functional status of platelets for wound healing applications, we identified two specific platelet markers, GPIb and annexin V.(22) Quiescent-nonactivated platelets circulate expressing the platelet glycoprotein GPIb, the ligand of Von Willebrand factor.(23) GPIb positive platelets have extended in vivo survival when infused and the ability to deliver growth factors.(24) Upon activation, platelets rearrange the cytoskeleton, lose the GPIb glycoprotein and express annexin $\mathrm{V}$, a marker associated with procoagulant activity(25) and the release of growth factors.(26-28) Annexin $V$ positive platelets undergo apoptosis and are rapidly removed by tissue macrophages.(29) Platelet GPIb and annexinV binding to platelets correlate with in vivo survival and function.(25) The expression of platelet GPIb correlated with the capacity of platelets to stimulate specific mechanisms such as angiogenesis, as in RT and FZ6 preparations. The results suggest that the quiescent platelet preparations may exert a specific stimulatory role in wound healing, rather than just deliver a bolus of growth factors as originally thought. (8) Since only the preparations containing quiescent platelets stimulated wound healing this role may be related to intact platelets membranes that functioned as systems to deliver growth factors at the appropriate time. Additional studies will further elucidate this hypothesis and characterize the effects of the preservation methods on the single growth factors. The concomitant increase in cell proliferation may have been a consequence of the development of new functional vessels or the direct effect of specific interaction between cells and platelets derived cytokines.

Wound healing is produced by growth factors. The clinical use of recombinant growth factors for recalcitrant wounds has yielded mixed results, mainly related to granulation tissue formation.(30) Activated platelets produced by freezing without DMSO and storage at $-80^{\circ}$ $\mathrm{C}$, the activated portion of the bimodal population produced by freezing with DMSO and storage at $-80^{\circ} \mathrm{C}$, and thrombin activated platelets produce granulation tissue formation. Clinically, the mechanism of granulation tissue formation in wound healing and whether it should be promoted or not have not yet been clearly determined.

Quiescent platelets have a crucial role in stimulating angiogenesis and cell proliferation in wound healing. Platelets preserved in the liquid state at room temperature for 2 days and platelets frozen with $6 \%$ DMSO by storage at $-80 \mathrm{C}$ provide a self-controlled drug delivery system able to modulate wound healing and angiogenesis without the need to add thrombin to these platelet products. The use of platelets frozen with $6 \% \mathrm{DMSO}$ by storage at $-80{ }^{\circ} \mathrm{C}$ is a simple procedure to have available therapeutically effective platelets to treat chronic wounds in diabetic patients.

\section{Acknowledgments}

Authors thank Drs. Herbert Hechtman and John Vournakis for useful discussion. Batool Salem is acknowledged for excellent technical assistance.

\section{References}

1. Complications of Diabetes in the United States. www.idf.org/home/index.cfm

2. Falanga V. Wound healing and its impairment in the diabetic foot. Lancet 2005;366:1736-1743. [PubMed: 16291068]

3. Pietramaggiori G, Kaipainen A, Ho D, Orser C, Pebley W, Rudolph A, Orgill DP. Trehalose lyophilized platelets for wound healing. Wound Repair Regen 2007;15:213-220. [PubMed: 17352753] 
4. Scherer SS, Pietramaggiori G, Mathews JC, Prsa M, Huang S, Orgill DP. The mechanism of action of the Vacuum Assisted Closure Device. Plast Reconstr Surg. in Press.

5. Folkman J, Browder T, Palmblad J. Angiogenesis research: guidelines for translation to clinical application. Thrombosis and haemostasis 2001;86:23-33. [PubMed: 11487011]

6. Gnatenko DV, Perrotta PL, Bahou WF. Proteomic approaches to dissect platelet function: Half the story. Blood 2006;108:3983-3991. [PubMed: 16926286]

7. Eppley BL, Pietrzak WS, Blanton M. Platelet-rich plasma: a review of biology and applications in plastic surgery. Plast Reconstr Surg 2006;118:147e-159e.

8. Knighton DR, Ciresi KF, Fiegel VD, Austin LL, Butler EL. Classification and treatment of chronic nonhealing wounds. Successful treatment with autologous platelet-derived wound healing factors (PDWHF). Ann Surg 1986;204:322-330. [PubMed: 3753059]

9. Italiano JE Jr. Richardson JL, Patel-Hett S, Battinelli E, Zaslavsky A, Short S, Ryeom S, Folkman J, Klement GL. Angiogenesis is regulated by a novel mechanism: Pro- and anti-angiogenic proteins are organized into separate platelet $\{$ alpha\}-granules and differentialy released. Blood. 2007

10. Ma L, Perini R, McKnight W, Dicay M, Klein A, Hollenberg MD, Wallace JL. Proteinase-activated receptors 1 and 4 counter-regulate endostatin and VEGF release from human platelets. Proc Natl Acad Sci U S A 2005;102:216-220. [PubMed: 15615851]

11. Bennett SP, Griffiths GD, Schor AM, Leese GP, Schor SL. Growth factors in the treatment of diabetic foot ulcers. Br J Surg 2003;90:133-146. [PubMed: 12555288]

12. Frechette JP, Martineau I, Gagnon G. Platelet-rich plasmas: growth factor content and roles in wound healing. J Dent Res 2005;84:434-439. [PubMed: 15840779]

13. Singer AJ, Clark RA. Cutaneous wound healing. N Engl J Med 1999;341:738-746. [PubMed: 10471461]

14. Ma L, Hollenberg MD, Wallace JL. Thrombin-induced platelet endostatin release is blocked by a proteinase activated receptor-4 (PAR4) antagonist. British journal of pharmacology 2001;134:701704. [PubMed: 11606309]

15. Said HK, Hijjawi J, Roy N, Mogford J, Mustoe T. Transdermal sustained-delivery oxygen improves epithelial healing in a rabbit ear wound model. Arch Surg 2005;140:998-1004. [PubMed: 16230552]

16. Steed DL. Clinical evaluation of recombinant human platelet-derived growth factor for the treatment of lower extremity ulcers. Plast Reconstr Surg 2006;117:143S-149S. discussion 150S-151S. [PubMed: 16799381]

17. Steed DL, Goslen JB, Holloway GA, Malone JM, Bunt TJ, Webster MW. Randomized prospective double-blind trial in healing chronic diabetic foot ulcers. CT-102 activated platelet supernatant, topical versus placebo. Diabetes Care 1992;15:1598-1604. [PubMed: 1468291]

18. Driver VR, Hanft J, Fylling CP, Beriou JM, Autologel Diabetic Foot Ulcer Study, G. A prospective, randomized, controlled trial of autologous platelet-rich plasma gel for the treatment of diabetic foot ulcers. Ostomy Wound Manage 2006;52:68-70. 72, 74. passim. [PubMed: 16799184]

19. Hoffmeister KM, Josefsson EC, Isaac NA, Clausen H, Hartwig JH, Stossel TP. Glycosylation restores survival of chilled blood platelets. Science 2003;301:1531-1534. [PubMed: 12970565]

20. Valeri CR, Ragno G, Khuri S. Freezing human platelets with 6 percent dimethyl sulfoxide with removal of the supernatant solution before freezing and storage at -80 degrees $C$ without postthaw processing. Transfusion 2005;45:1890-1898. [PubMed: 16371041]

21. Pietramaggiori G, Scherer SS, Mathews JC, Alperovich M, Yang HJ, Neuwalder J, Czeczuga JM, Chan RK, Wagner CT, Orgill DP. Healing modulation induced by freeze-dried platelet-rich plasma and micronized allogenic dermis in a diabetic wound model. Wound Repair Regen 2008;16:218225. [PubMed: 18318807]

22. Barnard MR, MacGregor H, Ragno G, Pivacek LE, Khuri SF, Michelson AD, Valeri CR. Fresh, liquid-preserved, and cryopreserved platelets: adhesive surface receptors and membrane procoagulant activity. Transfusion 1999;39:880-888. [PubMed: 10504125]

23. Ni H, Freedman J. Platelets in hemostasis and thrombosis: role of integrins and their ligands. Transfus Apher Sci 2003;28:257-264. [PubMed: 12725952]

24. Valeri CR, Ragno G, Khuri S. In vitro effects of polymerized N-acetyl glucosamine (NAG) on the activation of platelets in platelet rich plasma with and without red blood cells. J Trauma (suppl) 2004;57:S22-S25. 
25. Xiao HY, Matsubayashi H, Bonderman DP, Bonderman PW, Reid T, Miraglia CC, Gao DY. Generation of annexin V-positive platelets and shedding of microparticles with stimulus-dependent procoagulant activity during storage of platelets at 4 degrees C. Transfusion 2000;40:420-427. [PubMed: 10773053]

26. Becker GA, Tuccelli M, Kunicki T, Chalos MK, Aster RH. Studies of platelet concentrates stored at 22 C nad 4 C. Transfusion 1973;13:61-68. [PubMed: 4695593]

27. Slichter SJ, Harker LA. Preparation and storage of platelet concentrates. Transfusion 1976;16:8-12. [PubMed: 3000]

28. Valeri CR. Hemostatic effectiveness of liquid-preserved and previously frozen human platelets. N Engl J Med 1974;290:353-358. [PubMed: 4810115]

29. Wu JR, Zhou C, Majumder R, Powers DD, Weinreb G, Lentz BR. Role of procoagulant lipids in human prothrombin activation. 1. Prothrombin activation by factor $\mathrm{X}(\mathrm{a})$ in the absence of factor $\mathrm{V}$ (a) and in the absence and presence of membranes. Biochemistry 2002;41:935-949. [PubMed: 11790117]

30. Chan RK, Liu PH, Pietramaggiori G, Ibrahim SI, Hechtman HB, Orgill DP. Effect of recombinant platelet-derived growth factor (Regranex) on wound closure in genetically diabetic mice. J Burn Care Res 2006;27:202-205. [PubMed: 16566566] 
a

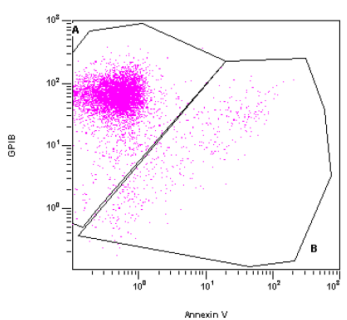

RT b

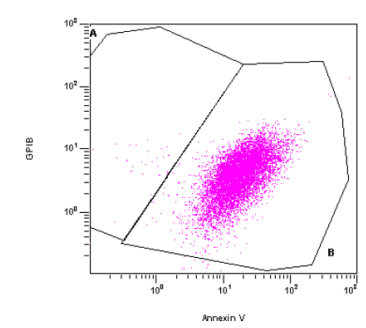

$\mathrm{FZ}$

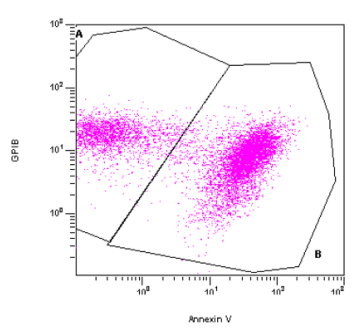

FZ6

Figure 1. Effects of platelet preservation on platelet GPIb and Annexin $\mathbf{V}$ binding

a. RT showed a homogenous population positive for GPIb and negative for annexin $\mathrm{V}$ binding. b. FZ had $80 \%$ annexin $\mathrm{V}$ positive platelets, minimal number of GPIb positive platelets and $20 \%$ platelet microparticles after thawing c. FZ6 had a bimodal population with $33 \% \mathrm{GPIb}$ positive platelets and $50 \%$ annexin $\mathrm{V}$ positive platelets and only $9 \%$ platelet microparticles. $\mathrm{RT}=$ Liquid preserved platelets stored at room temperature for 2 days; $\mathrm{FZ}=$ platelets frozen without DMSO at $-80 \mathrm{C}$ after thawing; FZ6=platelets frozen with $6 \% \mathrm{DMSO}$ at $-80 \mathrm{C}$ after thawing. 
a

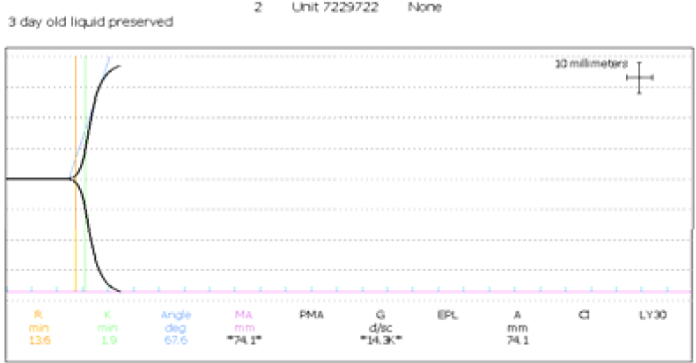

RT

Liquid preserved concentrated $\quad 2 \quad$ Unit $7229722 \quad$ None

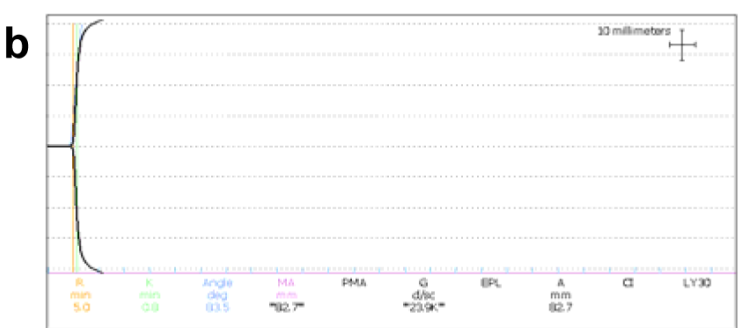

\section{RT Concentrated}

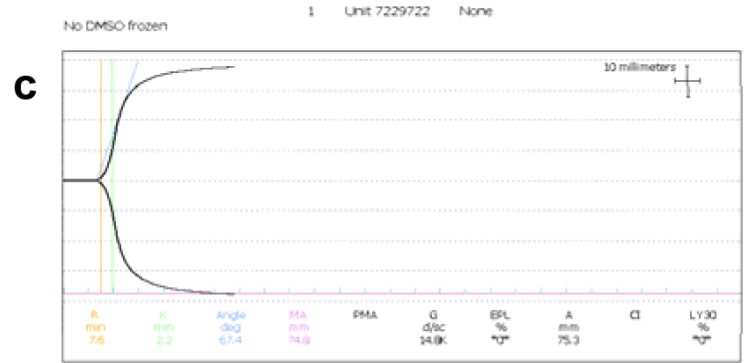

FZ

unt 7229722 None

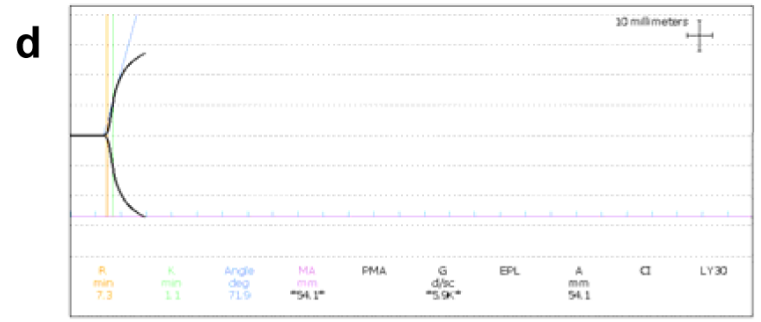

FZ6

Figure 2. Effects of platelet preservation and the concentration of platelets on the $\mathbf{R}$ time measured in the thromboelastogram

a. RT had an R value of 13.6 minutes. b. The concentration of RT to $1 \times 109$ platelets per $\mathrm{ml}$ reduced the $\mathrm{R}$ value from 13.6 minutes to 5 minutes. c,d. FZ and FZ6 had R values of 7.3 and 7.6 minutes. 


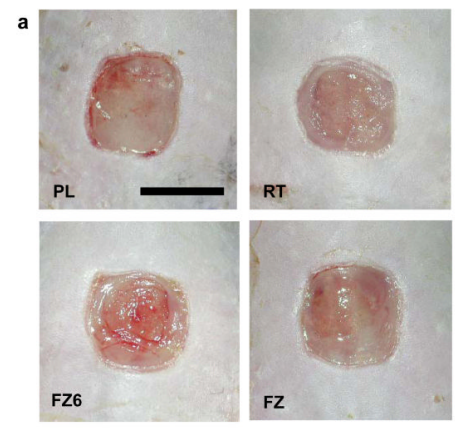

b Wound Closure

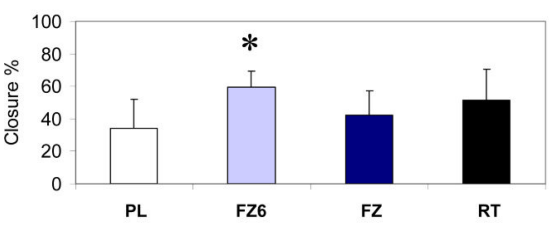

c

Wound Contraction

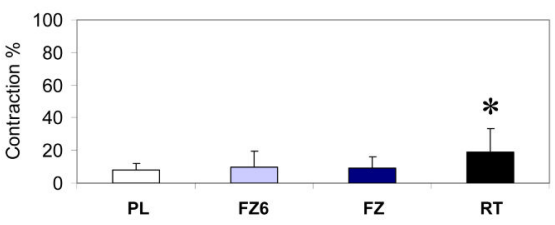

Wound Re-Epithelialization

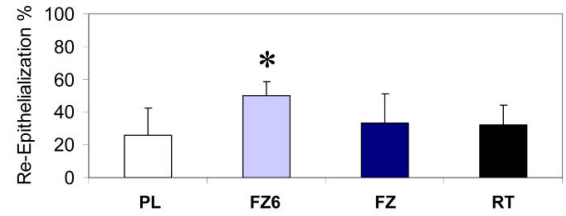

Figure 3. Effect of plasma and platelet preparations on wound healing

$100 \mu \mathrm{l}$ of a sample containing $1 \times 109$ platelets per $\mathrm{ml}$ or plasma were applied in single dose on day 0 . a. Plasma alone did not stimulate wound closure, while RT stimulated healing. FZ6 induced greater stimulation of wound closure compared to plasma, RT and FZ. b. The platelet products produced an increase in wound closure compared to plasma. FZ6 produced the highest level of wound closure on day 7. c. RT produced a two-fold increase of contraction on day 7 compared to the other treatments. d. FZ6 produced a 2-fold increase in wound reepithelialization compared to plasma on day 7. Scale Bar $5 \mathrm{~mm}$. Results are expressed as mean \pm SD. $*=$ p $<0.05$ compared to PL. RT=Liquid preserved platelets stored at room temperature for 2 days; FZ=platelets frozen without DMSO at $-80 \mathrm{C}$ after thawing; FZ6=platelets frozen with $6 \% \mathrm{DMSO}$ at $-80 \mathrm{C}$ after thawing; $\mathrm{PL}=$ plasma. 

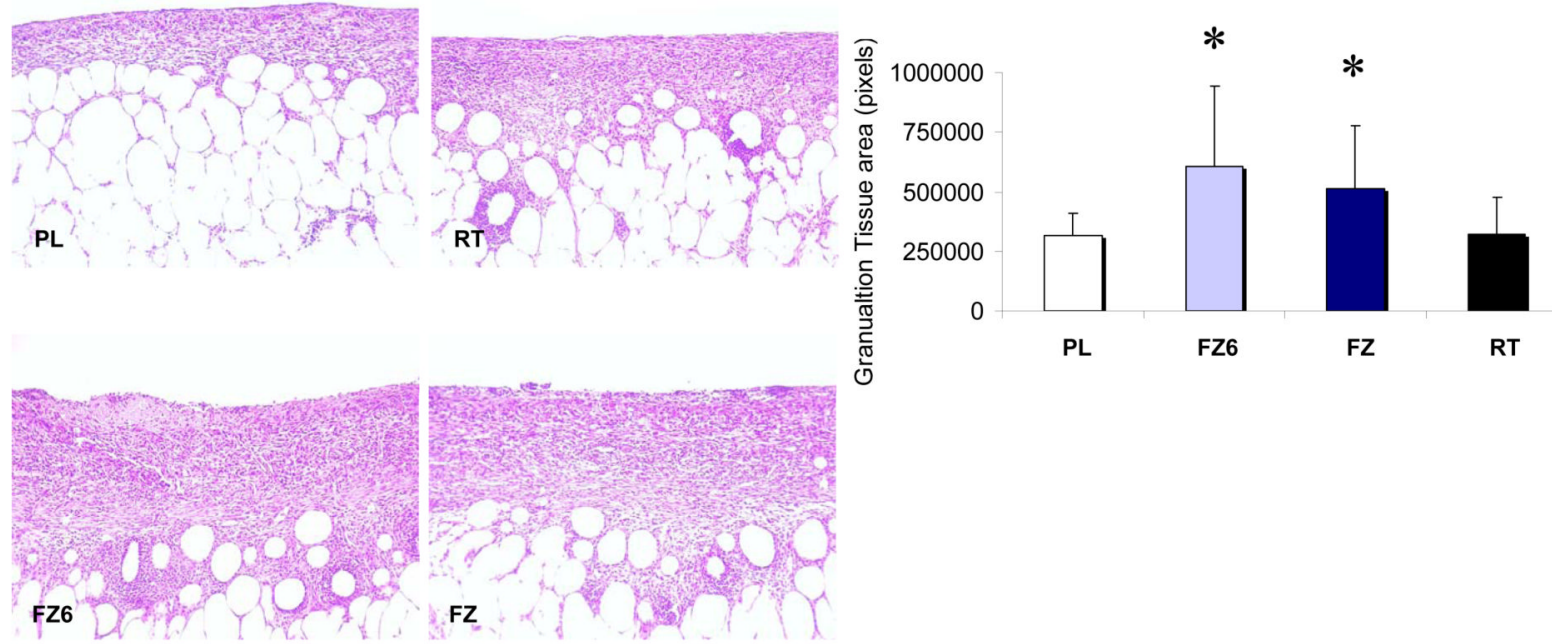

PL

FZ6

$\mathrm{FZ}$

RT

b

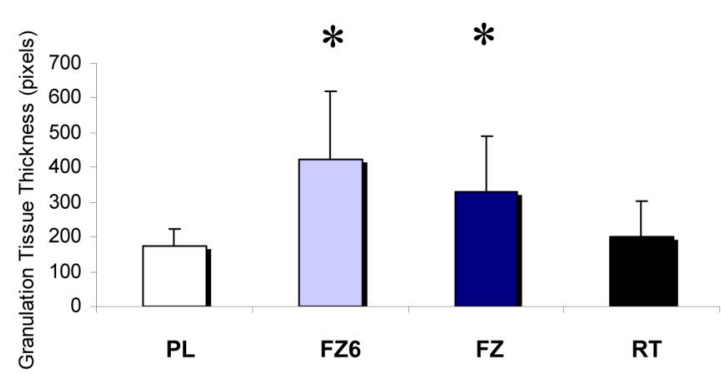

Figure 4. Effect of plasma and platelet preparations on granulation tissue formation a. $100 \mu \mathrm{l}$ of the sample contains $1 \times 109$ platelets per ml FZ6 and FZ increased the thickness of the granulation tissue by 2.5 and 1.9 times, respectively, when compared to plasma alone. The area of granulation tissue also increased 1.9 and 1.6 times following treatment with FZ6 and FZ b,c. Quantification of the results. Results are expressed as mean \pm SD. $*=p<0.05$, compared to PL. 
a
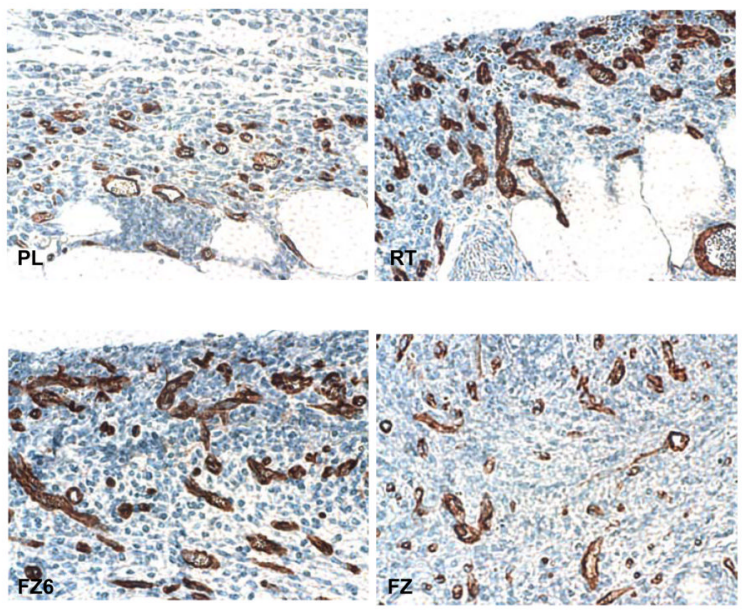

b

Blood Vessels/HPF

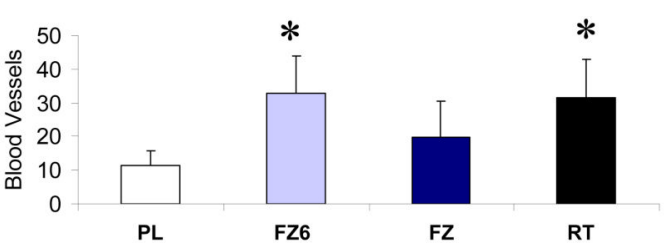

Figure 5. Effect of plasma and platelet preparations on wound vascularity

a. $100 \mu \mathrm{l}$ of sample containing $1 \times 109$ platelets per $\mathrm{ml} \mathrm{FZ6} \mathrm{and} \mathrm{RT} \mathrm{induced} \mathrm{an} \mathrm{increase} \mathrm{in} \mathrm{wound}$ vascularity compared to PL alone, as assessed by the panendothelial marker (PECAM-1) b. A 2.9 and 2.8 increase in wound vascularity was induced by FZ6 and RT compared to PL. Results are expressed as mean \pm SD. $*=p<0.05$ compared to PL. 
a

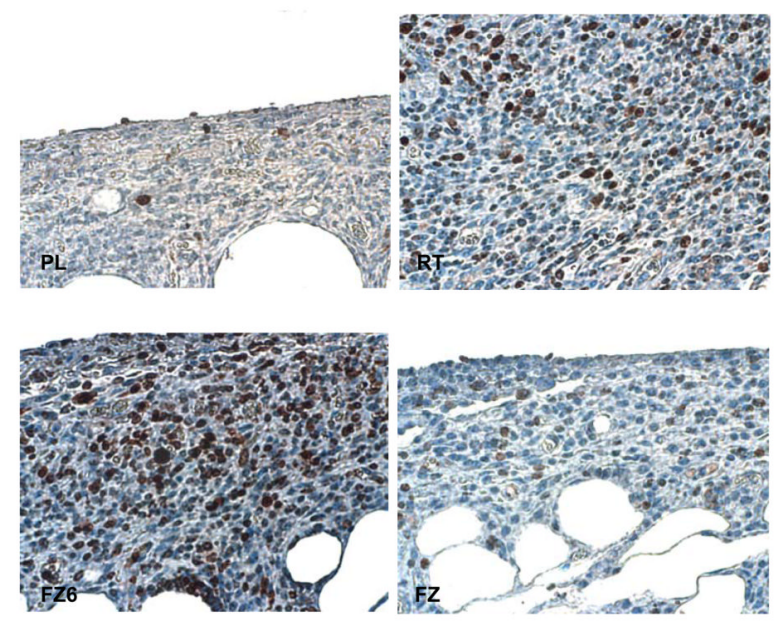

b

Cell Proliferation \%

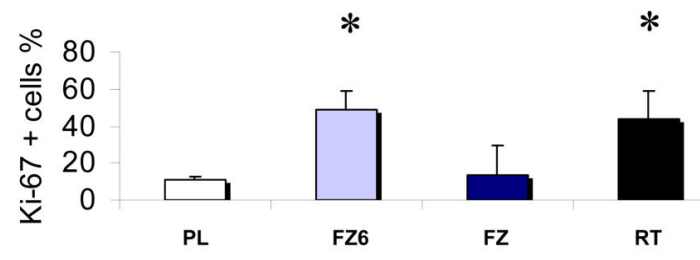

Figure 6. Effect of plasma and platelet preparations on cell proliferation

a. $100 \mu \mathrm{l}$ of sample containing $1 \times 109$ platelets per ml FZ6 and RT increased cell proliferation assessed by Ki 67 positively compared to plasma alone. b. Quantification of the results. Results are expressed as mean $\pm \mathrm{SD} . *{ }^{*}=\mathrm{p}<0.05$ compared to PL. 
Wound Watch

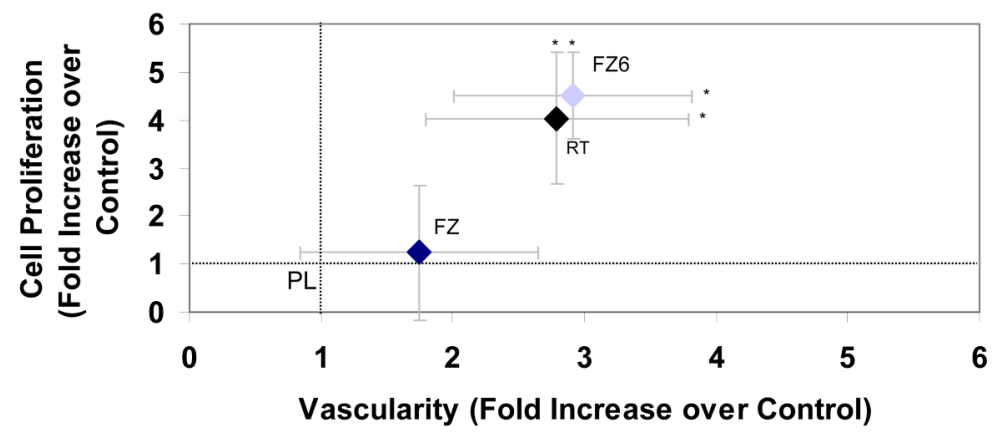

Figure 7. Wound healing staging system

Immunohistochemical results are plotted to obtain a two-dimensional wound staging system for healing on day 7. Vascularity was assessed by measurement of PECAM-1, a pan-endothelial marker and cell proliferation was assessed by measurement of Ki-67, a marker for cell proliferation. Three distinct wound healing profiles were noted: plasma showed the lower stimulation of both parameters (arbitrary set to 1), RT and FZ6 stimulated both parameters in a similar manner, while results from FZ fell in between these two groups. Results are expressed as mean \pm SD. $*=p<0.05$ compared to PL. 